\title{
Impact of the conditional cash transfer program on the monthly food expenditure of household beneficiaries
}

Norberto E. Milla ${ }^{\text {* }}$

\begin{abstract}
Submitted: 1 June 2019 | Accepted: 24 March 2020

Philippines is among the many countries which has a perennial problem on poverty. The country has made various ways to reduce its poverty rate; one is through conditional cash transfer (CCT) scheme. This study measured the impact of CCT Program, particularly on food consumption among its household beneficiaries using Propensity Score Matching (PSM). Impact is measured in terms of the Average Treatment Effect on the Treated (ATT) using four matching algorithms: Nearest Neighbor Matching, Caliper (Radius) Matching, Kernel Matching, and Local Linear Regression matching. Binary logistic regression was used to identify covariates influencing program participation which include having children who are 6-12 years old, education of the household heads' spouses, marital status and sex of the household head, housing tenure, and ownership of household assets. Balance test indicates nonsignificant difference between 4Ps and non-4Ps beneficiaries across these covariates. Of the four matching algorithms, the Caliper (radius) matching generated ATT estimate with the least standard error. On the average, using the Caliper matching method, the monthly food expenditure of the household beneficiaries have significantly increased by PHP501.39. Thus, the CCT program of the government has brought significant improvement on the household beneficiaries, not only on education, health, and nutrition but also on their monthly food expenditure. It is recommended that the implementation of the CCT program should be strengthened, sustained, and maintained properly and orderly to gradually alleviate the current poverty conditions in the identified poor barangays around the nation. Moreover, the implementing agencies should consistently monitor the proper and synchronized implementation of the program in order to wholly purge the intergenerational transmission of poverty which is a perennial experience of the households who belong to the poorest populace in the country.
\end{abstract}

Keywords: propensity score matching, nearest neighbor matching, caliper matching, kernel matching, local linear regression matching

'Department of Statistics, Visayas State University, Baybay City, Leyte, Philippines

\footnotetext{
*Corresponding Author. Address: Department of Statistics, Visayas State University, Baybay City, Leyte, Philippines; Email: bertmilla@vsu.edu.ph

DOI: 10.32945/atr4218.2020
} 
Impact of the conditional cash transfer program

\section{INTRODUCTION}

Developing countries around the world experience a number of challenges on different aspects such as, poverty, health, education, economy, etc. However, despite these challenges, they made extraordinary efforts to address these challenges. Agbon et al (2013) reported that governments in many developing countries adopted the conditional cash transfer (CCT) scheme at a prodigious rate to alleviate short-term poverty and reduce the intergenerational transmission of poverty. For the past two decades, conditional cash transfer (CCT) programs have gained enormous popularity both as a mechanism for inclusive social protection and as a strategy for breaking the cycle of poverty (Tutor 2014). The program grants low-income families the opportunity to receive financial support, provided they keep their children in school and maintain their health through regular check-ups. The program positively drives poor families to invest more in human capital, particularly on children. This approach is considered both as an alternative to more traditional social assistance programs and a demand-side complement to the supply of health and education services (Rawlings \& Rubio 2005).

In the 2000 Millennium Declaration, the Philippines was among the many countries which committed to reduce its poverty rate by year 2015 (Reyes \& Tabuga 2012). The Philippines has adopted the CCT program to primarily eradicate extreme poverty in the country and promote social development and human capital formation among the poor and vulnerable households by investing in health and education. The program provides financial assistance to the so-called 'poorest of the poor' families (Tabilog et al 2017), which is mainly identified by the PSA office. Moreover, the poorest of the poor around the Philippine archipelago have the worst health condition (Frufonga 2015) and this is one of the reasons for the adoption of the CCT program. Regardless of the many attempts of the government to meet this commitment, the country's poverty incidence continues to increase from 24.9 percent in 2003 to 26.4 percent in 2006 and increased slightly to 26.3 percent in 2009 (PSA 2009) despite launching of a localized version of the conditional cash transfer (CCT) scheme in 2007. The Philippine version of CCT is known as the Pantawid Pamilyang Pilipino Program (4Ps). This program is considered one of the strategies to alleviate poor provinces from poverty. It began with a target of 6,000 households from the 20 poorest provinces of the country. Families with children having 0-14 years old or pregnant women can receive a monthly cash grant of PHP500 to PHP1400 for a maximum of 5 years. Reyes et al (2013) purported that the program served as a cornerstone of the government's poverty reduction and social development strategy which aimed to improve beneficiaries' health, nutrition, and education, particularly of children aged 0-14 years old. Moreover, the program also aimed to raise the average consumption rate on the food expenditure of poor households (Pantawid Pamilya Operations Manual 2012). In fact, the program aimed to increase food expenditures in the household by 4 percent (DSWD 2009).

The Pantawid Pamilya helped to fulfill the country's commitment to meeting some of the Millennium Development Goals (MDG). These MDGs include eradicating extreme poverty, achieving universal primary education, promoting gender equality, reducing child mortality, and improving maternal health. DSWD (2011) reported that the government estimates indicated that 26.5 percent of the population was living below the poverty line in 2009 , which was lower than the 
baseline figure of 33.1 percent in 1991 but still far from the target of 16.6 percent by 2015. Progress in achieving MDG targets in education and health has also been slow. In 2008, the net enrolment ratio in primary education was 85.1 percent, and only 75.4 percent of those in school were able to start Grade 1 and reach Grade 6. The number of maternal deaths per 100,000 live births was 162 in 2006, more than three times the target of 52.3 , while only 79.2 percent of one-year-old children were immunized against measles in 2008 (NSCB 2011).

The 4Ps is by far the largest poverty reduction and social development program the Philippine government has ever implemented (Reyes et al 2015). Based on the PSA (2016) reports, the poverty incidence has declined from 26.3 percent in 2009 to 25.2 percent in 2012 and further down to 21.6 percent in 2015. This significant reduction in poverty incidence could be attributed to the implementation of the 4Ps program. This fact is affirmed by Fernandez and Olfindo's (2011) report which indicated that since the inception of the CCT program in the Philippines in 2007, the government successfully rolled out to reach the poorest households in the Philippines.

The studies of Tacare (2017) and Chaudhury et al (2012) evaluated the impact of 4Ps along the program's success indicators using PMS and RCT, respectively. In the study of Chaudhury et al (2012), the randomized control trials (RCT) methodology was employed to evaluate the impact of 4Ps on several outcome variables, which included food consumption. Likewise, Frufonga's (2015) investigation focused on the improvement brought by the implementation of 4Ps. Its result revealed that there is a reduction of malnourished children and improvements in the preventive healthcare among pregnant women and younger children. Meanwhile, in the study of Tacare (2017), the propensity score matching (PSM) was utilized to evaluate the impact of 4Ps; however, the study focused on the savings behavior of the beneficiaries.

In this study, food consumption counts and relates to all types of goods that are conditioned-on by the program. In the local context, no studies were conducted focusing on the impact of 4Ps on the household beneficiaries' monthly food consumption; thus, this study was conducted to assess the impact of 4Ps specifically on the aggregate monthly food consumption of beneficiaries using propensity score matching.

\section{MATERIALS AND METHODS}

\section{Data}

This study was conducted in Sabang Bao, Ormoc City, Leyte. This barangay is one of the identified poorest barangays in Ormoc City. This is the recipient of the CCT program and has the first set of 4Ps household beneficiaries - the population of interest - of this study. It has 180 households, of which 79 are 4Ps household beneficiaries and 101 are non-beneficiaries. Complete enumeration was implemented to all the 4Ps beneficiaries and random selection to the nonbeneficiaries. This was so to directly compare the impact of the 4Ps program on the food consumption between the 4Ps household beneficiaries and non-beneficiaries who lived in the same barangay. The sample population is enough to obtain the estimate on the impact of the 4Ps program on the monthly food consumption 
Impact of the conditional cash transfer program

of the household beneficiaries and compare it to the food expenditure of the nonbeneficiaries.

Data on socio-demographic characteristics of household heads and their spouses, dwelling characteristics, ownership of home assets, estimated monthly expenditure on basic food items, and other items were collected using a questionnaire. Average monthly food consumption is reckoned for all types of food items (ie, carbohydrate \& protein food, fruits, vegetables, \& other foods). Other food includes cooking oil, sugar, salt, non-alcoholic beverages, and other seasoning items. The consumption data for each expenditure item is the sum of cash or credit expenses.

\section{Measurement of Impact}

There are several quantitative methods for measuring impact of projects and programs. In this paper, propensity score matching (PSM) is used to measure the impact of the 4Ps program on the food expenditure of beneficiary households. Propensity score methods allow investigators to estimate causal treatment effects using observational or nonrandomized data (Austin 2011). The steps in PSM include: selection of covariates, propensity score estimation, construction of the region of common support, testing covariate balance, matching beneficiaries to non-beneficiaries, and estimation of program impact.

\section{Selection of Covariates}

Estimation of treatment effect using PSM starts by estimating the propensity scores. There are two widely used model specifications in estimating the propensity scores: logit regression model and probit regression model. These are the most popular models for use with dichotomous dependent variables. In this research, the logit model was used since it is considered to be the more versatile model. The full model as applied in this study is expressed as:

$$
P_{i}=E\left(Y_{i}=1 \mid X_{i}\right)=\frac{e^{\beta_{0}+\beta_{i} X_{i}}}{1+e^{\beta_{0}+\beta_{i} X_{i}}}=\beta_{0}+\beta_{1} X_{1}+\ldots+\beta_{p} X_{p}+\varepsilon
$$

where: $\quad Y=1$, if 4 Ps beneficiary; $=0$, if non-beneficiary

$P_{i}=$ probability of a household being included in the program

$E=$ the expected value of being in the program given the covariates

$\beta_{0}=$ unknown intercept parameter

$\beta_{i}=$ regression coefficients, $i=1,2, \ldots, p$

$X=$ matrix of covariates or the predictor variables

$\mathrm{p}=$ number of covariates

Only covariates that are found significant in predicting program inclusion using the estimated logistic regression model were included in the estimation of propensity scores. 


\section{Propensity Score Estimation}

Rosenbaum and Rubin (1983) defined the propensity score as the conditional probability of receiving a treatment given pretreatment characteristics. For this study, the treatment is the 4Ps. The full propensity score model is expressed as:

$$
p_{i}=p\left(X_{i}\right)=P(D=1 \mid X)
$$

where: $\quad X=$ multidimensional vector of covariates

$D=\{0,1\}$ indicator of 4 Ps exposure

$p_{i}=$ propensity score

\section{Common Support Region}

The average treatment effect on the treated (ATT) is only defined in the region of common support. Hence, it is very important to check the region of common support between beneficiaries and non-beneficiaries. Implementing the common support condition ensures that any combination of the characteristics observed in the beneficiary group can also be observed among the non-beneficiary group. Here, maxima and minima approach was used in identifying the range of common support. The basic criterion of this approach is to delete all observations whose propensity score is smaller than the minimum and larger than the maximum in the opposite group. In addition, the software (Stata) automatically split the sample into $k$ equally spaced intervals of the propensity scores. The $k$ intervals are known as the blocks of propensity scores. Within each block, testing that the means of each characteristic do not differ between beneficiaries and non-beneficiaries was done using T-test.

\section{Testing the Covariate Balance}

Since we do not condition on all covariates but on the propensity score, it has to be checked if the matching procedure is able to balance the distribution of the relevant variables or covariates in both the comparison and treatment group after matching. The standardized bias procedure was used for this study since it generates a visual representation which is comprehensible. The standardized bias after matching isgiven by:

$$
S B_{\text {after }}=100 \times \frac{\bar{X}_{1 M}-\bar{X}_{0 M}}{\sqrt{0.05\left[V_{1 M}(X)+V_{0 M}(X)\right]}}
$$

where:

$$
\begin{aligned}
\bar{X}_{1 M} & =\text { the mean in the beneficiary group after matching } \\
\bar{X}_{O M} & =\text { the mean in the non-beneficiary group after matching } \\
V_{1 M}(X) & =\text { corresponding values of the beneficiary matched sample } \\
V_{0 M}(X) & =\text { corresponding values of the beneficiary matched sample }
\end{aligned}
$$

\section{Matching Algorithms}

Beneficiaries were matched to non-beneficiaries based on the "closeness" of their propensity scores. Various matching algorithms have been proposed in the literature for use in propensity score matching and three of the most widely used are 
Impact of the conditional cash transfer program

Nearest-Neighbor Matching, Radius Matching, and Kernel Matching. Nearestneighbor is the most straightforward matching estimator since individual from the comparison group is chosen as a matching partner for a treated individual that is closest in terms of propensity score. Radius matching is an alternative to nearestneighbor. Here, tolerance level is imposed on the maximum propensity score distance (caliper) where individual from comparison group is chosen as matching partner for a treated individual that lies within the caliper (propensity range) and is closest in terms of propensity score. Lastly, Kernel matching is a non-parametric estimator that uses weighted averages of all individuals in the control group to construct the counterfactual outcome.

\section{Estimation of Program Impact: Average Treatment Effect on the Treated(ATT)}

The PSM estimator for ATT is simply the mean difference in outcomes between beneficiaries and non-beneficiaries over the common support, appropriately weighted by the propensity score distribution of treated group. The general form is presented as:

$$
\tau_{A T T}^{P S M}=E_{p(x) \mid P=1}\left\{E\left[Y_{1}\left|P=1, p(x)-Y_{0}\right| P=0, p(x)\right]\right\}
$$

$$
\begin{aligned}
& \text { where: } \quad \tau_{A T T}^{P S M}=\text { PSM estimator of ATT } \\
& p(x)=\text { propensity scores } \\
& \mathrm{P}=\text { dichotomous response, where } \mathrm{P}=1 \text { if beneficiary and } 0 \text { if otherwise } \\
& Y_{1}=\text { food consumption expenditure of 4Ps beneficiary } Y \\
& Y_{0}=\text { food consumption expenditure of 4Ps non-beneficiary } Y
\end{aligned}
$$

\section{RESULTS AND DISCUSSION}

\section{Profile of 4Ps household beneficiaries and household non-beneficiaries}

The respondents of this study were compared in terms of household composition and food consumption, household head and spouse characteristics, dwelling characteristics, and household assets.

On the average, 4Ps beneficiaries have larger household size with 6 members while the non-beneficiaries only have 4 members. The household beneficiaries have more children within the age group eligible for the 4Ps program. Likewise, household beneficiaries have higher food consumption with an average monthly food expenditure of PHP3,581.65. Moreover, majority of the household heads for both beneficiary and non-beneficiary groups are males. Almost two thirds of the heads of the beneficiary households and approximately half of the heads of nonbeneficiary households are married. In addition, 82.28 percent and 72.28 percent of the heads of the beneficiary and non-beneficiary households, respectively, are employed. In terms of educational attainment, 63.29 percent and 47.52 percent of the heads of the beneficiary and the non-beneficiary households, respectively, have elementary education; less than half of them attended high school, while very few of them have college education. On the other hand, 6.33 percent and 10.89 percent of the spouses of the heads of beneficiary and non-beneficiary households, respectively, have no formal education. More than half of the spouses of the non- 
beneficiaries and almost half of the spouses of the non-beneficiary household heads have elementary education. Meanwhile, the proportion of spouses with high school education is almost the same for both respondents. Similar to household heads, very few of the spouses, both for beneficiary and non-beneficiary households, have college education.

As regards to household dwellings, both the respondents have roofs and walls made of light materials. Nonetheless, almost 40 percent of the household beneficiaries have roofs made of heavy materials, which is comparatively higher in number than the non-beneficiaries. In addition, both respondents own their houses and they are located on a rent-free land but with consent from the land owner. Further, 30.4 percent of the beneficiary households and 24.8 percent of the nonbeneficiary households have no electricity connection. In addition, almost all respondents have closed pit toilet while the remaining less than 20 percent of both the respondents do not own a toilet. Concerning their water source, nearly all of the respondents have connections to Ormoc Waterworks and Sewerage Administration (ORWASA), the main water source of all inhabitants of Ormoc City. ORWASA is Ormoc City's water system project which provides potable water to households on monthly-basis payment. However, despite the city's water system project, there are still households who get water for household use from deep well or water pumps. In fact, 18.8 percent of the non-beneficiaries and 2.5 percent of the beneficiaries get their water source from wells.

With reference to their household assets, six household appliances, such as electric fan, audio player, motorcycle, refrigerator, DVD player, and TV set were identified as acquired by the home owners. In particular, more than half $(62.8 \%)$ of the non-beneficiaries and only 37.2 percent of the beneficiaries have an electric fan. Almost all of the non-beneficiaries and 5.9 percent of the beneficiaries own an audio player. A number (57.1\%) of the non-beneficiaries have motorcycle, refrigerator, DVD player, and TV set. Thus, considering this data, 4Ps beneficiaries are relatively poorer than non-beneficiaries in terms of the household assets.

\section{Covariates of Program Participation}

The results of the logit regression to identify significant covariates of program participation is presented in Table 1. Having children 6-12 years old, which is within the age group eligible for the program, is significant in predicting program participation. The coefficient implies that a one-unit increase in the number of children 6-12 years old increases the logit of being a program beneficiary. In addition, the odds of being a program beneficiary is 2.41 times greater in households with more children 6-12 years old. Educational attainment of the spouse of the household head is also significant, with those having no education 99.38 times more likely in the program than those who have at least elementary education. In addition, households whose head is married is 8.22 times more likely in the program. Furthermore, households headed by men have 9.43 times greater probability of inclusion in the program than households headed by women.

In terms of housing tenure and source of water, households who own their house on rent-free land with consent from the land owner is 5.26 times more likely in the program, and households who get their water for household use from deep well are less likely to be in the program. On the other hand, owning a DVD and audio player are significant in predicting non-participation, as shown by the negativelysigned estimates on these covariates. This indicates that DVD and audio player are 
Impact of the conditional cash transfer program

0.09 and 0.02 times less likely owned by 4Ps beneficiaries, respectively. Results show that these covariates significantly affect probability of participation in the Pantawid Pamilyang Pilipino Program and are consistent with program's targeting mechanism.

Table 1. Binary Logistic Model Estimates (Outcome variable $=1$ if beneficiary; 0 , otherwise)

\begin{tabular}{|c|c|c|}
\hline Covariates & $\beta$ & $\operatorname{Exp}(\beta)$ \\
\hline \multicolumn{3}{|l|}{ HH composition } \\
\hline Household size & 0.516 & 1.675 \\
\hline No. of $\mathrm{HH}$ members $0-2$ years old & -0.856 & 0.425 \\
\hline No. of $\mathrm{HH}$ members $3-5$ years old & 0.807 & 2.241 \\
\hline No. of $\mathrm{HH}$ members 6-12 years old & $0.880 *$ & 2.411 \\
\hline No. of $\mathrm{HH}$ members $13-18$ years old & 0.268 & 1.307 \\
\hline \multicolumn{3}{|l|}{$\mathrm{HH}$ head and Spouse characteristics } \\
\hline Age of $\mathrm{HH}$ head & 0.038 & 1.039 \\
\hline$=1$ if head is male & $2.244^{\star}$ & 9.431 \\
\hline$=1$ if $\mathrm{HH}$ head is married & $2.107^{\star \star}$ & 8.224 \\
\hline$=1$ if $\mathrm{HH}$ head is self-employed & 0.141 & 1.151 \\
\hline$=1$ if $\mathrm{HH}$ head had some high school & -1.439 & 0.237 \\
\hline$=1$ if $\mathrm{HH}$ head had some college & -0.292 & 0.747 \\
\hline$=1$ if spouse had no education & $4.599 \star \star$ & 99.385 \\
\hline$=1$ if spouse had some high school & 1.404 & 4.071 \\
\hline$=1$ if spouse had some college & -2.479 & 0.084 \\
\hline \multicolumn{3}{|l|}{ Dwelling characteristics } \\
\hline Floor area $\left(\mathrm{m}^{2}\right)$ & 0.004 & 1.004 \\
\hline$=1$ if dwelling wall made of light materials & 20.733 & $1.01 \times 10^{9}$ \\
\hline$=1$ if dwelling roof made of light materials & -1.382 & 0.251 \\
\hline$=1$ if $\mathrm{HH}$ has electricity & -0.946 & 0.388 \\
\hline$=1$ if $\mathrm{HH}$ has closed pit toilet & 0.849 & 3.337 \\
\hline = 1 if $\mathrm{HH}$ own house, rent-free lot $\mathrm{w} /$ owner's & $1.660^{*}$ & 5.259 \\
\hline \multicolumn{3}{|l|}{ Dummies for $n-1$ categories of water source } \\
\hline Deep well community water system & $-3.710 * \star$ & 0.024 \\
\hline Water pump & -0.945 & 0.389 \\
\hline \multicolumn{3}{|l|}{ Dummies for $n-1$ categories of types of housing unit } \\
\hline Combination of concrete \& wood & -0.297 & 0.743 \\
\hline Mainly concrete & 25.111 & $8.05 \times 10^{10}$ \\
\hline \multicolumn{3}{|l|}{$\mathrm{HH}$ assets } \\
\hline$=1$ if $\mathrm{HH}$ has at least $1 \mathrm{DVD}$ player & $-2.411^{\star}$ & 0.09 \\
\hline$=1$ if $\mathrm{HH}$ has at least 1 refrigerator & -2.777 & 0.062 \\
\hline$=1$ if $\mathrm{HH}$ has at least 1 audio player & $-3.849 *$ & 0.021 \\
\hline$=1$ if $\mathrm{HH}$ has at least 1 motorcycle & 1.722 & 5.596 \\
\hline$=1$ if $\mathrm{HH}$ has at least 1 electric fan & 0.812 & 2.252 \\
\hline$=1$ if $\mathrm{HH}$ has at least $1 \mathrm{TV}$ & -1.035 & 0.355 \\
\hline
\end{tabular}

$\mathrm{x}^{2}=136.266 ; 0<0.01 ;-2 \mathrm{LL}=108.917 ;$ Cox \& Snell- $\mathrm{R}^{2}=0.533 ;$ Nagelkerke- $\mathrm{R}^{2}=0.715$;

* - significant at $5 \%$ level; $* \star$ - significant at $1 \%$ level; $n=180$

\section{Propensity Score Estimates}

The common support region ensured that the propensity score is balanced across beneficiary and non-beneficiary households. Figure 1 shows the distribution 
of propensity scores among beneficiary and non-beneficiary households within and outside the range of common support. The figure shows the extent to which the distributions of propensity scores in beneficiary and non-beneficiary groups within the on-support region overlap. All the propensity scores within this region indicate that any combination of characteristics observed in the beneficiary group can also be observed among the non-beneficiary group. Hence, the characteristics of these two groups are more likely the same. The blue bars in the figure below specify the propensity scores which were on the off-support region. Twenty-six (26) households were on the off-support region and these all belong to nonbeneficiaries. These households were consequently excluded in the estimation of the average treatment effect. In other words, average treatment effect was estimated using 79 beneficiary households and 75 non-beneficiary households.

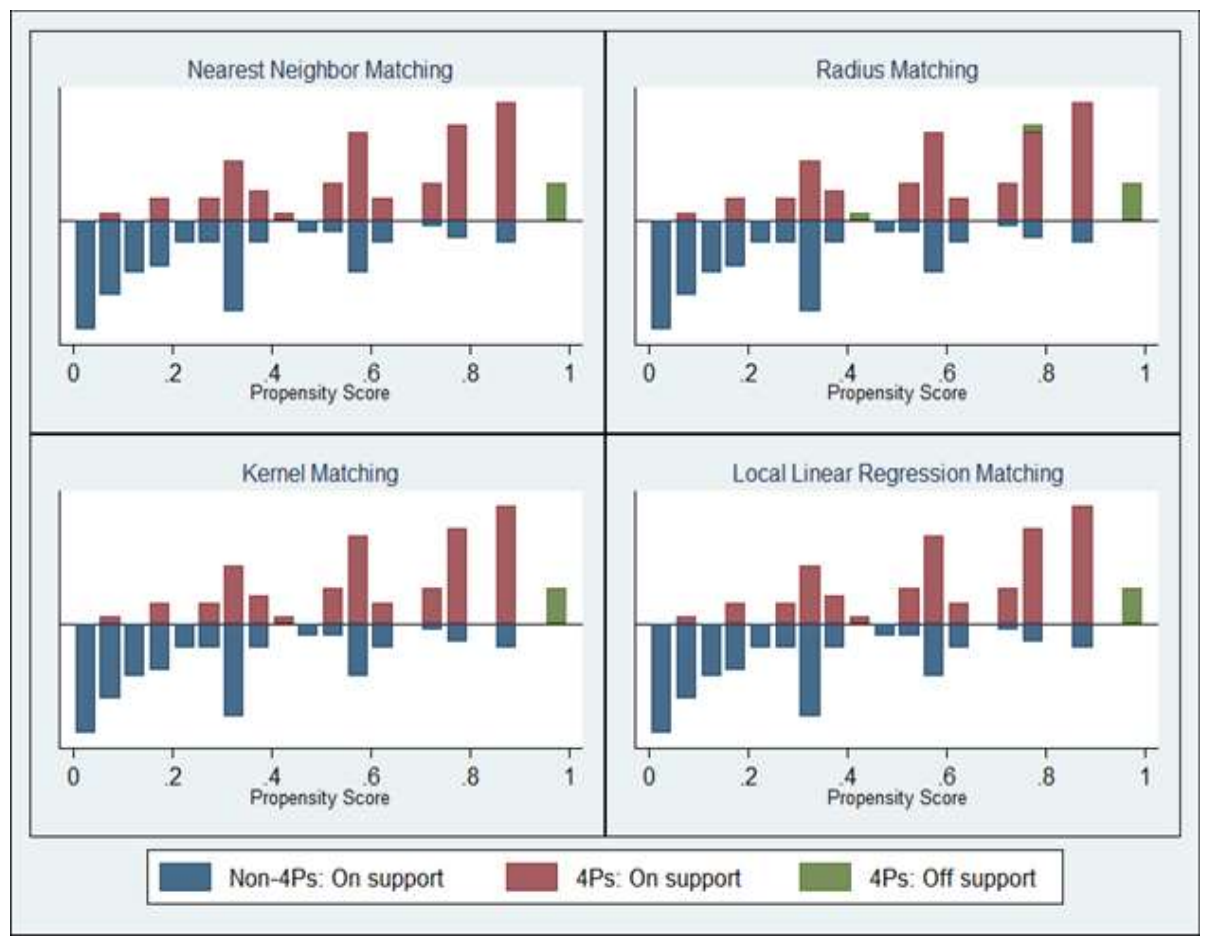

Figure 1. Propensity Score Distribution of Households On- and Off-Support Region

In the common support region, the treated (4Ps) and the control (non-4Ps) must, on the average, be balanced across the covariates in the propensity score model after matching. Results of the covariate balance test are presented in Table 2. Across different matching method, the p-values associated with the t-tests in comparing the 4Ps and non-4Ps households are all greater than 0.05 . This implies that the two groups are statistically matched across different covariates. Another way to ensure that covariate balance is achieved after matching is to look at the standard bias. As shown in Table 2, the mean absolute standard bias is very small (less than 10\%). This implies that after matching, standard difference between the two groups are largely negligible. 
Impact of the conditional cash transfer program

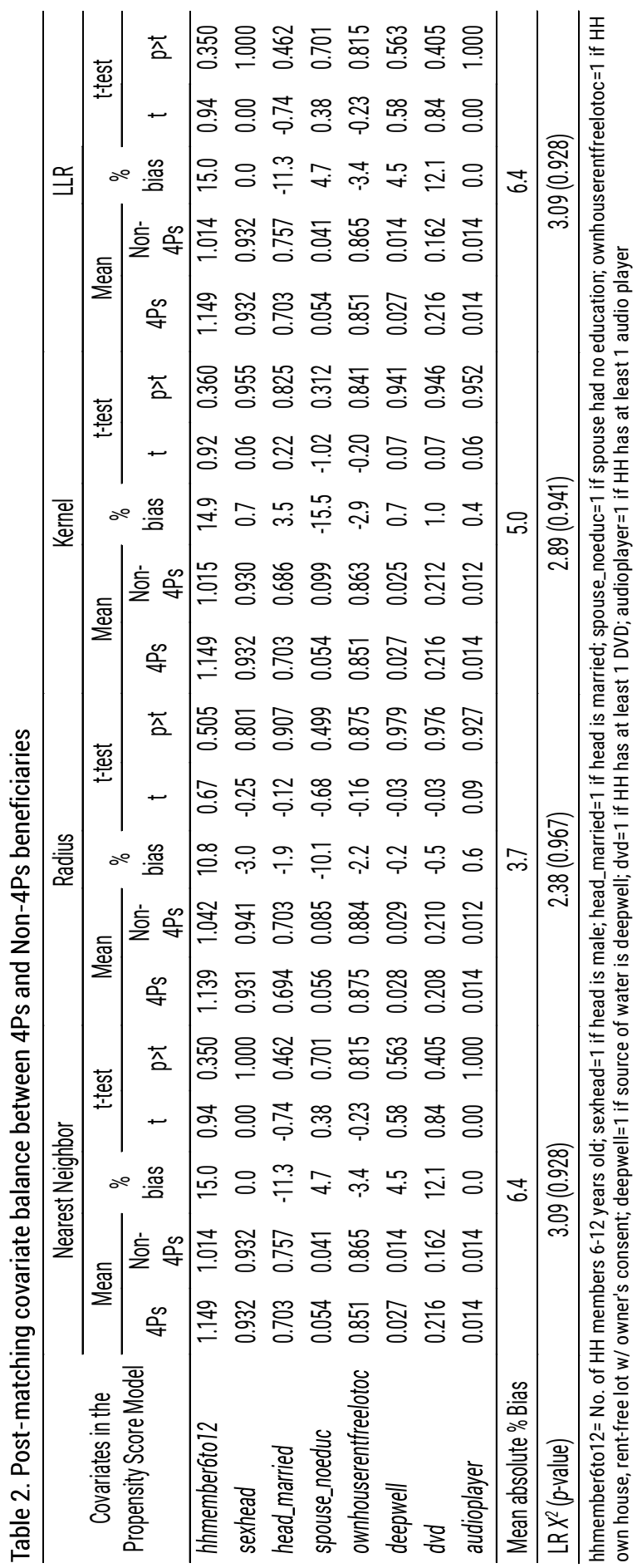




\section{Estimates of Program Impact}

Based on the estimates in Table 3, the conditional cash transfer has positive impact on food consumption. That is, food consumption expenditure of beneficiary households increased after participating in the program. The monthly increase was as low as 338.50 (nearest neighbor) to as high as 501.39 (caliper). Of the four matching methods, Caliper (radius) matching generated the largest ATT estimate and the smallest standard error. Although, the performance of different matching estimators varies case by case and depends largely on the data structure at hand (Baser 2006), it seems that Caliper matching method outperforms the other three algorithms in terms of the standard error of the estimate.

In 2015 each household with three (3) children was expected to receive a monthly cash of PHP1,400.00 from the 4Ps program. Based on the results, the estimated average treatment effect corresponds to about a third of the maximum cash incentive household beneficiaries can receive. This simply means that beneficiaries allocated a third of the cash incentive they receive from the program to feed their hungry stomach. This finding is supported by Tutor (2014) who said that after spending for goods conditioned by the CCT program, household beneficiaries spent the remaining amount on food.

Table 3. Average treatment effect of conditional cash transfer on food consumption

\begin{tabular}{ccccccc}
\hline Matching method & ATT & SE* $^{\star}$ & $\mathrm{Z}$ & $\mathrm{P}>\mathrm{Z}$ & \multicolumn{2}{c}{ 95\% Conf. Interval } \\
\hline Nearest neighbor & 338.50 & 317.69 & 1.07 & 0.287 & -284.15 & 961.17 \\
Caliper (radius) & 501.39 & 217.03 & 2.31 & 0.021 & 76.016 & 926.77 \\
Kernel & 468.39 & 245.30 & 1.91 & 0.056 & -12.38 & 949.16 \\
Local linear regression & 458.53 & 242.65 & 1.89 & 0.059 & -17.06 & 934.12 \\
\hline
\end{tabular}

*based on bootstrap runs of 1000 replications

$\mathrm{n}=154$ ( 79 beneficiaries, 75 non-beneficiaries)

\section{CONCLUSIONS}

After five years of the implementation of the conditional cash transfer among poor household beneficiaries of the barangay, it has brought about a positive impact on the food consumption, an aggregate of all types of food items bought and consumed every day that are conditioned-on by the program, among the beneficiaries. The food consumption expenditure of the beneficiary households increased after they have participated in the program. Even though the cash incentive they received monthly from the program was not intended entirely for food, the beneficiaries apportioned a third part of the cash to be added on their budget for food; thus, providing more food for the entire household.

By and large, the conditional cash transfer program of the Philippine government has brought great impact in improving the household beneficiaries' living condition, ie, not only on their primary education, health, and nutrition, but also on their food consumption. Hoddinott and Skoufias (2004) purported that in other countries, the impact evaluation on the CCT programs was found effective to reduce poverty by 17 percent in Progresa communities in Mexico, while the Familias en Acción program in Colombia has reduced the poverty gap by more than 6 percentage points. Moreover, Fernandez and Olfindo (2011) reported that the cash 
Impact of the conditional cash transfer program

household incomes of the poor, while the conditionalities have helped improve the education and health of their children.

Evidently, the 4Ps operates in a political environment where there is a high possibility of corruption and where all policies involved in this program are highly politicized as well. The government offices are marred by corruption allegations and government programs, whether big or small in terms of budget, are plagued by a number of bribery incidences (Arulpragasam et al 2011). Since the program involves cash transfers in such a political environment, it is highly recommended that its implementation in the local context should be strengthened, sustained, and maintained properly and orderly to gradually attain the government's goal, that is, to alleviate the current poverty conditions in the identified barangays around the nation. Moreover, the implementing agencies should regularly and religiously monitor the proper, consistent, and synchronized implementation of the program in order to wholly purge the intergenerational transmission of poverty which is a perennial experience of the households who belong to the poorest populace in the country.

\section{REFERENCES}

Agbon A, Nolasco FA, Aguilar EJT, Abellanosa RJ \& Ligaton L. 2013. Pantawid Pamilyang Pilipino Program (4Ps): Examining Gaps and Enhancing Strategies in Cebu City, Philippines. East Asia Development Network

Austin PC. 2011. A tutorial and case study in propensity score analysis: An application to estimating the effect of in-hospital smoking cessation counseling on mortality. Multivariate Behavioral Research 46(1):119-151

Arulpragasam J, Fernandez L, Matsuda Y, Olfindo R \& Stephens M. 2011. Building governance and anti-corruption in the Philippines' conditional cash transfer program. World Bank Social Protection Note no. 1. World Bank, Washington, DC

Baser 0.2006 . Too much ado about propensity score models? Comparing methods of propensity score matching. Value health 9(6):377-385

Department of Social Welfare and Development (DSWD) Report. 2013. FAQs on the conditional cash transfer program

Department of Social Welfare and Development (DSWD). 2011. National household targeting system for poverty reduction

Fernandez $L$ and Olfindo R. 2011. Overview of the Philippines' conditional cash transfer program: The pantawid pamilyang Pilipino program (Pantawid Pamilya). World Bank Social Protection Policy Note no. 2. World Bank, Washington, DC

Frufonga RF. 2015. The pantawid pamilyang pilipino program (4Ps) in Iloilo, Philippines: An evaluation. Asia Pacific Journal of Multidisciplinary Research 3(5):59-65

GADM and Department of Social Welfare and Development (DSWD) Report. 2014. Philippines: Region 8 households under 4Ps

Hoddinott $\mathrm{J}$ and Skoufias E. 2004. The impact of Progresa on food consumption. Economic Development and Cultural Change 53(1):37-61

National Statistical Coordination Board (NSCB). 2011. Philippine poverty statistics

Philippine Statistics Authority (PSA). 2009. 2009 official poverty statistics of the Philippines 
Philippine Statistics Authority (PSA). 2016. 2015 official poverty statistics of the Philippines

Rawlings $L$ and Rubio G. 2005. Evaluating the impact of conditional cash transfer programs

Reyes CM and Tabuga AD. 2012. Conditional cash transfer program in the Philippines: is it reaching the extremely poor? Discussion Paper Series No. 2012-42. Philippine Institute of Development Studies

Reyes CM, Tabuga AD, Mina CD \& Asis RD. 2015. Promoting inclusive growth through the 4Ps. Research Paper Series No. 2015-01. Philippine Institute for Development Studies

Reyes CM, Tabuga AD, Mina CD \& Asis RD. 2013. Promoting inclusive growth through the 4Ps

Rosenbaum $P$ and Rubin D. 1985. The central role of the propensity score in observational studies for causal and effects. Biometrika 70(1):41-55

Tabilog RP, Mapola MMB, Cantillano CD, Cabrera MC \& Mañabo RD. 2017. Pantawid pamilyang pilipino program (4Ps): The effectiveness on social welfare and development. 11th International Conference on Law, Education, Business and Management (LEBM-17) Dec. 17-18, 2017 Manila (Philippines)

Canare T. 2017. The Impact of conditional cash transfer on savings and other associated variables: Evidence from the Philippines' 4Ps program. Southeast Asian Journal of Economics 5(1):107-145

Tutor MV. 2014. The impact of Philippines' conditional cash transfer program on consumption. UP School of Economics Discussion Papers 201405, University of the Philippines School of Economics 